\title{
Prevalence of schistosomiasis and its association with anemia among pregnant women: a systematic review and meta-analysis
}

\author{
Ishag Adam ${ }^{1}$, Nadiah A. ALhabardi ${ }^{1}$, Osama Al-Wutayd ${ }^{2}$ (ID and Ammar H. Khamis ${ }^{3}$
}

\begin{abstract}
Background: Schistosomiasis is a highly prevalent parasitic disease that can lead to adverse maternal and perinatal outcomes. To our knowledge, there has been no systematic review and meta-analysis of schistosomiasis during pregnancy.
\end{abstract}

Methods: We followed the Preferred Reporting Items for Systematic Reviews and Meta-Analyses guidelines. Relevant published studies were searched in international databases (PubMed, Science Direct, Scopus, Web of Science, and Google Scholar), from their inception until May 31, 2020. The retrieved studies were assessed for quality using the Modified Newcastle-Ottawa Scale. OpenMeta Analyst software was used for the statistical analysis.

Results: Thirty-two studies enrolling 21024 pregnant women were included in this meta-analysis. All 32 of these studies were conducted in Africa. Of these studies, 19, 11, and 2 investigated S. mansoni, S. haematobium, and combined S. mansoni and S. haematobium infections, respectively. The pooled prevalence estimate of schistosomiasis during pregnancy was $13.2 \%$ (95 Cl 11.0-15.4). A random model was used because of high heterogeneity $(\mathrm{Q}=99.14$; $P<0.001)$. In subgroup analyses, the pooled prevalence estimate of $S$. haematobium was significantly higher than the pooled prevalence estimates of S. mansoni [22.5\% (95\% Cl 1.6-43.5) vs 8.7\% (95\% Cl 6.0-11.3, $P=0.016)$, respectively]. The results of meta-regression analyses showed a non-significant difference in the prevalence of schistosomiasis during pregnancy according to the study sample sizes and year of publication. Only six studies evaluated the association between schistosomiasis during pregnancy and anemia. Schistosomiasis was associated with anemia in these six studies ( $\mathrm{OR}=3.02,95 \%=1.25-7.28, P=0.014)$.

Conclusion: The present meta-analysis suggests that schistosomiasis during pregnancy is an existing health problem. This meta-analysis also highlights the lack of data on the determinants and outcomes of schistosomiasis during pregnancy. Preventive measures are needed and could be part of antenatal care in areas endemic with schistosomiasis.

Keywords: Prevalence, Pregnancy, Schistosoma haematobium, Schistosoma mansoni

*Correspondence: O.alwutayd@qu.edu.sa

${ }^{2}$ Department of Family and Community Medicine, Unaizah College

of Medicine and Medical Sciences, Qassim University, Unaizah, Kingdom of Saudi Arabia

Full list of author information is available at the end of the article

\section{Introduction}

Schistosomiasis, also known as bilharzia, is a waterborne helminthic infection caused by parasitic flatworms belonging to Schistosoma spp. blood flukes. It is a highly prevalent parasitic disease worldwide that causes disease in over 200 million people, $90 \%$ of whom live in Africa [1]. The life cycle of schistosomes includes freshwater snails as intermediate hosts, from which infective cercariae

(c) The Author(s) 2021. This article is licensed under a Creative Commons Attribution 4.0 International License, which permits use, sharing, adaptation, distribution and reproduction in any medium or format, as long as you give appropriate credit to the original author(s) and the source, provide a link to the Creative Commons licence, and indicate if changes were made. The images or other third party material in this article are included in the article's Creative Commons licence, unless indicated otherwise in a credit line to the material. If material is not included in the article's Creative Commons licence and your intended use is not permitted by statutory regulation or exceeds the permitted use, you will need to obtain permission directly from the copyright holder. To view a copy of this licence, visit http://creativeco mmons.org/licenses/by/4.0/. The Creative Commons Public Domain Dedication waiver (http://creativecommons.org/publicdomain/ zero/1.0/) applies to the data made available in this article, unless otherwise stated in a credit line to the data. 
are released into fresh water and can penetrate unbroken human skin. Schistosomiasis is especially prevalent in countries with tropical climates and limited access to clean water [1]. It was estimated that, in 2014, 40 million women of reproductive age had schistosomiasis (Schistosoma haematobium, S. japonicum, and/or S. mansoni) [2]. During pregnancy, helminth infections, including schistosomiasis, can lead to modulation of the immune response (change from Th1 toward Th2), increasing the susceptibility of pregnant women to various infections, such as influenza, malaria, measles, and toxoplasmosis, and their severity and can further lead to immune modulation in newborns [3, 4]. Previous studies have reported that schistosomiasis in pregnancy is associated with anemia [5-7]. Moreover, schistosomiasis, especially the urogenital type, might lead to adverse outcomes, such as low birth weight deliveries, preterm deliveries, and infertility $[8,9]$. Although several studies on schistosomiasis during pregnancy have been conducted in different countries [6-8, 10-38], empirical estimates of the global disease burden during pregnancy are lacking. However, the estimation of the global burden of schistosomiasis during pregnancy is of paramount importance, as it will guide preventive measures and other interventions. The current systematic review and meta-analysis was conducted to estimate the pooled prevalence of schistosomiasis and its association with anemia among pregnant women.

\section{Methods}

We followed the Preferred Reporting Items for Systematic Reviews and Meta-Analyses (PRISMA) guidelines in this study [39]. The included studies were assessed by using the Joanna Briggs Institute Meta-Analysis of Statistics Assessment and Review Instrument (JBI-MAStARI) [40]. Two investigators (NAA and $\mathrm{HZH}$ ) independently searched and identified eligible studies. If there was disagreement, it was resolved by discussion with a third researcher (IA). The extracted data (author's name, year of publication, study site, type of study, number of pregnant women with schistosomiasis, and total number of pregnant women enrolled) were recorded in an Excel sheet (Additional file 1).

\section{Search strategy}

A comprehensive literature search was conducted in international databases (PubMed, Science Direct, Scopus, Web of Science, and Google Scholar, from their inception until May 31,2020) to evaluate the prevalence of schistosomiasis in pregnant women. The searches were performed using MeSH terms either alone or in combination: ["schistosoma," "schistosomiasis," "bilharzia," "bilharziasis" OR "Schistosoma mansoni" OR "Schistosoma haematobium" OR "Schistosoma japonicum" AND
("Prevalence" OR "Epidemiology") AND ("Pregnancy" OR "Pregnant women") AND ("Anemia" OR "Hemoglobin")]. The references of the included articles were searched further for more suitable articles.

Articles were included in the meta-analysis if they met the following inclusion criteria: all cross-sectional studies published in peer-reviewed journals and reporting the prevalence of schistosomiasis in pregnant women, full text or abstract, in the English language, and investigating at least one type/species of schistosomiasis using standard parasitological methods. Case reports, letters, animal studies, duplicates, reviews, and articles in languages other than English were excluded (Fig. 1).

The quality of each study was assessed using the Modified Newcastle-Ottawa Scale (NOS) for cross-sectional or case-control studies [41]. Three major domains-the selection of participants, comparability of study groups, and ascertainment of outcomes of interest in each study-were evaluated by the NOS, with a maximum of nine stars. High-quality studies were assigned if the NOS score was $\geq 7$ stars (Table 1 ).

\section{Statistical analysis}

We used OpenMeta Analyst software for Windows $[42,43]$ to perform the meta-analyses. The heterogeneity of the included studies was evaluated according to Cochrane Q and $I^{2} . I^{2}$ values of $25 \%, 50 \%$, and $75 \%$ were considered to represent low, moderate, and high heterogeneity, respectively [44]. The random-effects model was used in case of significant heterogeneity between studies; otherwise, the fixed-effects model (Mantel-Haenszel method) was used for analysis. The pooled prevalence of schistosomiasis and the $95 \%$ confidence interval (95\% CI) were recorded. Subgroup/meta-regression analysis (size of study, year of publication, and type of infection) was conducted to detect the source of heterogeneity. Moreover, the pooled OR and 95\% CI were computed for the association between schistosomiasis and anemia. Funnel plots and Egger's test were used to assess the publications. A $P$-value was considered statistically significant if it was $<0.05$.

\section{Result}

A total of 308 records were identified and 146 duplicated articles were removed. The remaining 162 records were screened using the titles and abstracts, and 121 were excluded. Full texts of 41 articles were then evaluated according to eligibility criteria. Nine articles were also excluded. Finally, 32 articles were included in the study as they passed the eligibility criteria and quality assessment (Fig. 1).

Thirty-two studies enrolling 21,024 pregnant women were included in this meta-analysis $[6-8,10-38]$. The 

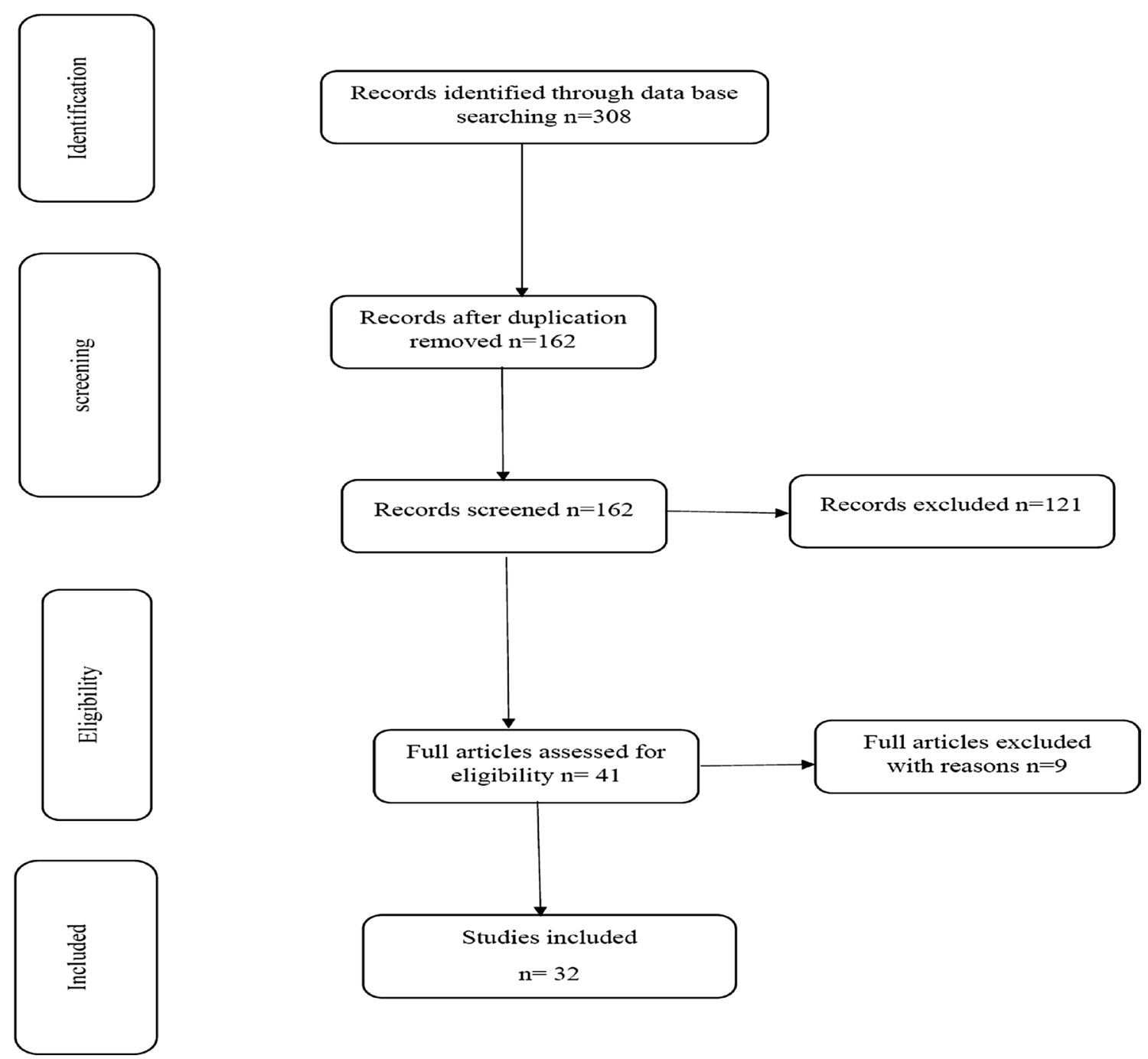

Fig. 1 Flow diagram showing the number of articles identified in the systematic review and meta-analysis of the prevalence of schistosomiasis during pregnancy.

sample size ranged from 120 [30] to 4437 pregnant women [19]. All of these studies were of high quality (Table 1).

\section{Countries}

All 32 of the studies were conducted in Africa. Six, five, and four studies were conducted in Ethiopia [11, 17, 24, $29,31,34]$, Nigeria [14, 20, 25, 30, 37], and Uganda [6, 12, $16,27]$, respectively. One study was conducted in Democratic Republic of Congo [15], Côte d'Ivoire [36], Sudan [10], Gabon [8], and Zimbabwe [19] (Fig. 2).

\section{Species}

Among these 32 studies, 19, 11, and 2 studies investigated S. mansoni $[7,10-12,16,17,22,24,26-31,33$,
34, 36-38], S. haematobium [8, 13-15, 18-21, 25, 32, 35], and combined infections of S. mansoni and S. haematobium [6,23], respectively.

\section{Prevalence}

The prevalence of schistosomiasis ranged from $0 \%$ in Ghana [33] to $63.0 \%$ in Tanzania [7]. The pooled prevalence estimate of schistosomiasis during pregnancy was 13.2\% (95\% CI 11.0-15.4). A random model was used because of high heterogeneity $(Q=99.14, P<0.001$; Fig. 3).

In subgroup analyses, the pooled prevalence estimate of S. haematobium was significantly higher than the pooled prevalence estimate of $S$. mansoni $(22.5 \%$ 
Table 1 Ottawa rating for included studies: (* OR ** means criteria fulfilled/maximum score $=9$ )

\begin{tabular}{|c|c|c|c|c|}
\hline Study & Selection & Comparability & Outcomes & Total \\
\hline Adewale et al. & $* * * *$ & $* *$ & $* *$ & 8 \\
\hline Ahenkorah et al. & $* * * *$ & $* *$ & $* * *$ & 9 \\
\hline Ajanga et al. & $* * * *$ & $* *$ & $* * *$ & 9 \\
\hline Alem et al. & $* * *$ & $* *$ & $* * *$ & 8 \\
\hline Anchang-Kimbi et al. & $* * * *$ & $* *$ & $* *$ & 8 \\
\hline Ayoya et al. & $* * * *$ & $* *$ & $* *$ & 8 \\
\hline Bolka et al. & $* * * *$ & $* *$ & $* *$ & 8 \\
\hline Coulibaly et al. & $* * * *$ & $* *$ & $* * *$ & 9 \\
\hline Derso et al. & $* * * *$ & $* *$ & $* * *$ & 9 \\
\hline Egwunyenga et al. & $* * * *$ & $* *$ & $* *$ & 8 \\
\hline Eyo et al. & $* * * *$ & $* *$ & $* *$ & 8 \\
\hline Fairley et al. & $* * * *$ & $* *$ & $* * *$ & 9 \\
\hline Feleke et al. & $* * * *$ & $* *$ & $* *$ & 8 \\
\hline Fuseini et al. & $* * * *$ & $* *$ & $* *$ & 8 \\
\hline Gadoth et al. & $* * * *$ & $* *$ & $* * *$ & 9 \\
\hline Gedefaw et al. & $* * * *$ & $* *$ & $* *$ & 8 \\
\hline Kawai et al. & $* * *$ & $* *$ & $* * *$ & 8 \\
\hline Kefiyalew et al. & $* * *$ & $* *$ & $* *$ & 7 \\
\hline Khalid et al. & $* * *$ & $* *$ & $* * *$ & 8 \\
\hline Kihara et al. & $* * * *$ & $* *$ & $* * *$ & 9 \\
\hline Mombo-Ngoma et al. & $* * * *$ & $* *$ & $* *$ & 8 \\
\hline Muhangi et al. & $* * * *$ & $* *$ & $* * *$ & 9 \\
\hline Murenjekwa et al. & $* * * *$ & $* *$ & $* *$ & 8 \\
\hline Ndyomugyenyi et al. & $* * * *$ & $* *$ & $* *$ & 8 \\
\hline Ouédraogo et al. & $* * * *$ & $* *$ & $* * *$ & 9 \\
\hline Oyeyemi et al. & $* * * *$ & $* *$ & $* * *$ & 9 \\
\hline Salawu et al. & $* * * *$ & $* *$ & $* *$ & 8 \\
\hline Siegrist et al. & $* * * *$ & $* *$ & $* *$ & 8 \\
\hline Tay et al. & $* * * *$ & $* *$ & $* * *$ & 9 \\
\hline Thigpen et al. & $* * * *$ & $* *$ & $* *$ & 8 \\
\hline Tonga et al. & $* * *$ & $* *$ & $* * *$ & 8 \\
\hline Wepnje et al. & $* * * *$ & $* *$ & $* *$ & 8 \\
\hline
\end{tabular}

(95\% CI 1.6-43.5) vs 8.7\% (95\% CI 6.0-11.3, $P=0.016$ ), respectively). A random model was used because of high heterogeneity $(Q=99.4, P<0.001$; Fig. 4$)$.

The results of the meta-regression analyses showed a non-significant difference in the prevalence of schistosomiasis during pregnancy based on the study sample size (coefficient $=-0.001,95 \% \mathrm{CI}:-0.001$ to $0.001, P=0.538)$ and year of publication $(C=-0.002$; 95\% CI: -0.010 to $0.007, P=0.697$ ) (Table 2). Egger's test showed probable publication bias $(P=0.005$; Fig. 5).

\section{Schistosomiasis and anemia}

Only six studies evaluated the association between schistosomiasis during pregnancy and anemia $[6,23$, 31-33, 35]. Schistosomiasis was associated with anemia in these six studies $(\mathrm{OR}=3.02,95 \%=1.25-7.28$, $P=0.014)$. A fixed model was used $(Q=72.7, P=$ 0.003; Fig. 6).

\section{Discussion}

The main finding of the current meta-analysis was that all the retrieved studies on schistosomiasis during pregnancy were conducted in Africa. Moreover, all these studies documented S. haematobium and S. mansoni infections without any reports of S. japonicum. SubSaharan African countries account for more than twothirds $(70 \%)$ of schistosomiasis cases. S. haematobium and S. mansoni infections predominate in Africa [45]. It is worth mentioning that epidemiological data on schistosomiasis during pregnancy are generally scarce in subSaharan Africa, as the majority of studies are conducted on schoolchildren [46]. We did not identify any articles on the prevalence of schistosomiasis during pregnancy outside of Africa (Southeast Asia of Latin America). Perhaps there are publications on schistosomiasis during pregnancy in these settings, but they are in languages other than English. We included only published articles in English, which could explain the presence of publication bias in our findings. In Latin America and Southeast Asia, the identified reports addressed the pathophysiology rather than the epidemiology of schistosomiasis during pregnancy $[4,47]$. However, in these settings in which there are no published articles on schistosomiasis during pregnancy, there are meta-analyses on schistosomiasis available for other age groups $[48,49]$. Moreover, a previous study on S. japonicum during pregnancy assessed the

Table 2 Subgroups and metaregression analysis of the factors associated with schistosomiasis during pregnancy

\begin{tabular}{lllll}
\hline Covariate & Coefficient & $95 \%$ confidence interval & Standard error & $P$ \\
\hline Size & -0.001 & -0.001 to 0.001 & $<0.001$ & -0.004 \\
Year of publication & -0.002 & -0.010 to 0.007 & 0.04 & 0.697 \\
Type of infection & 0.097 & 0.018 to 0.176 & 0.016 \\
\hline
\end{tabular}




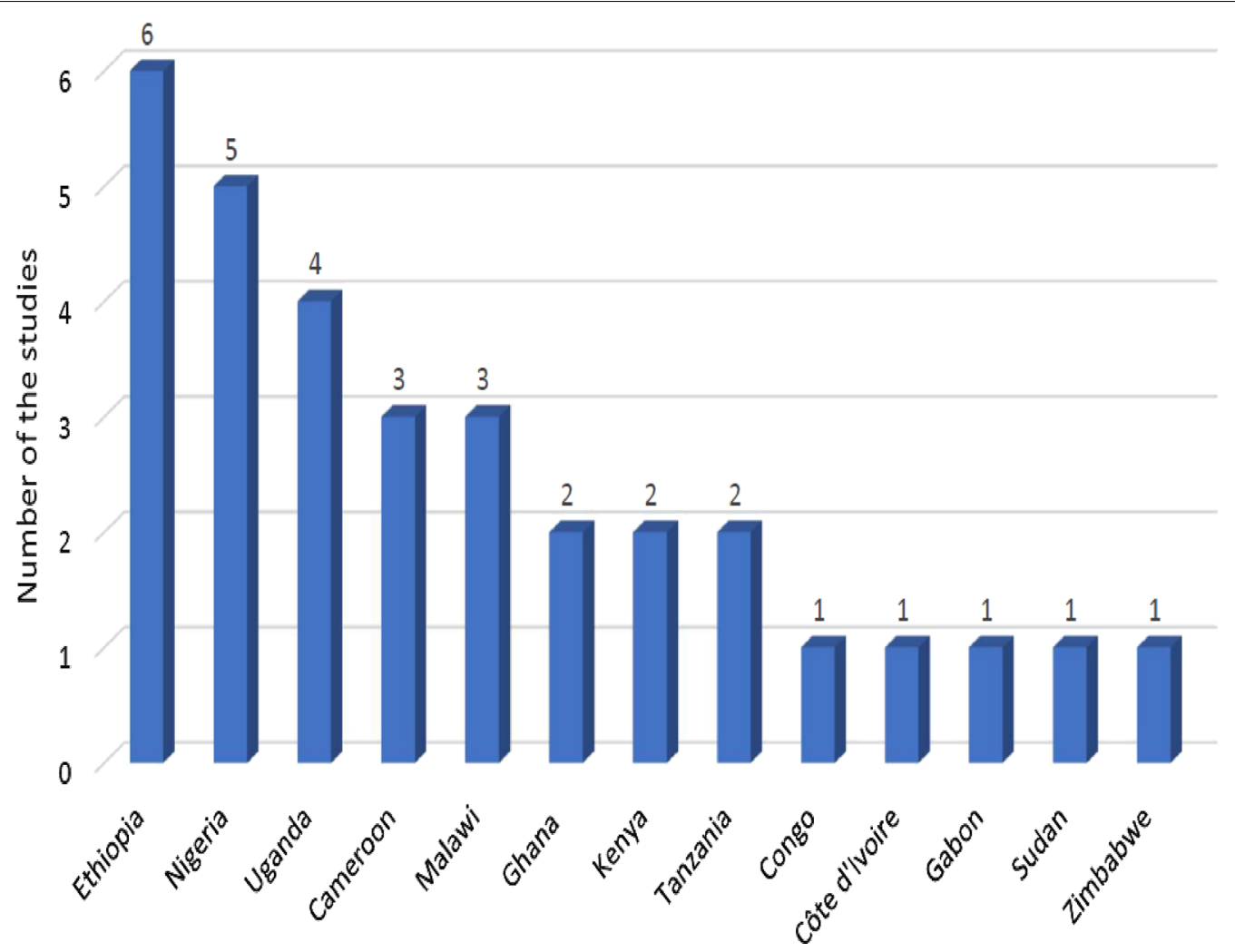

Fig. 2 Number of studies included from each country.

pathophysiology rather than the prevalence of schistosomiasis during pregnancy [50].

The current meta-analysis showed a pooled prevalence estimate of schistosomiasis during pregnancy of $13.2 \%$. A previous meta-analysis showed a reported pooled prevalence estimate for S. haematobium among adults of 54\% [51].

Although only six studies assessed the association between schistosomiasis and anemia, the current metaanalysis showed that pregnant women with schistosomiasis were at three times higher risk of anemia (pooled $\mathrm{OR}=3.02$ ). Previous studies have reported that schistosomiasis in pregnancy is associated with anemia [5-7]. In a systematic review and meta-analysis, Kassebaum et al. reported that malaria and schistosomiasis were the main conditions that increased the prevalence of anemia [53]. Although the exact pathophysiological mechanism of anemia and its associations with schistosomiasis have yet to be fully explained, hemolysis, inflammatory processes, and bone marrow suppression are plausible explanations for anemia and schistosomiasis [52]. Interestingly, few studies (six) assessed the association between schistosomiasis during pregnancy and anemia, and there was no available meta-analysis of this topic. It is possible that researchers do not feel it is important to document this association, and it might be considered an established fact rather than an area for research. A recent metaanalysis showed that mass deworming during pregnancy reduces maternal anemia by $23 \%$; however, there is no evidence of it having an impact on any other maternal or pregnancy outcomes [54].

Other effects of schistosomiasis on pregnancy outcomes, such as reduced maternal-to-infant antibody transfer [50, 55], infertility, preterm deliveries, and lower birth weights [9], need to be addressed. The adverse effects of schistosomiasis during pregnancy could be explained by the modulation of the immune response (change from Th1 toward Th2), which could be accompanied by immune modulation in newborns $[3,4]$.

Researchers might have investigated schistosomiasis epidemiology and its treatment (praziquantel) among children [56]. Regarding praziquantel safety during pregnancy, it was long indicated that "no data during pregnancy" were available. Following our reports on praziquantel safety during pregnancy $[57,58]$, it has come to be indicated as a safe, effective drug [59]. 


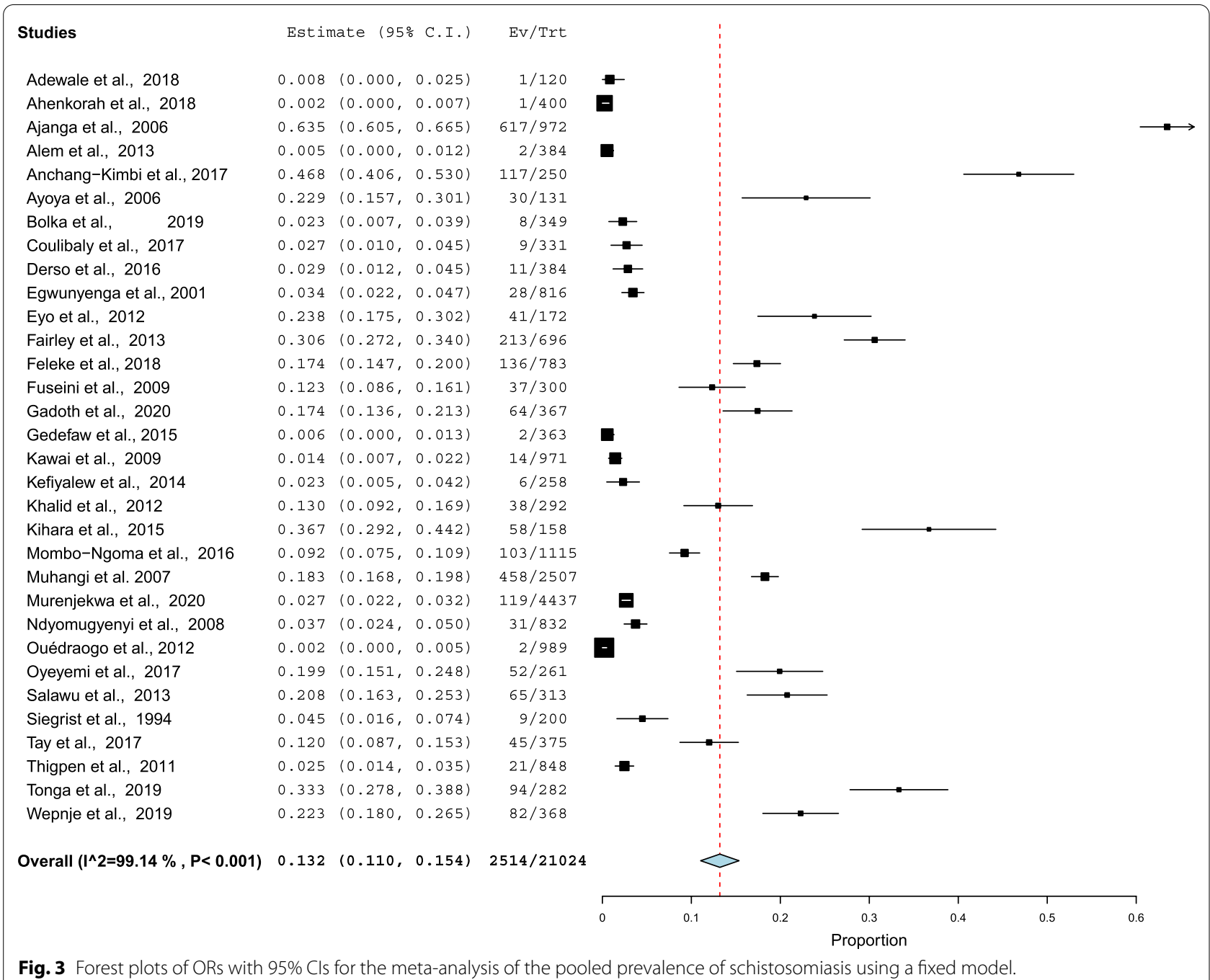




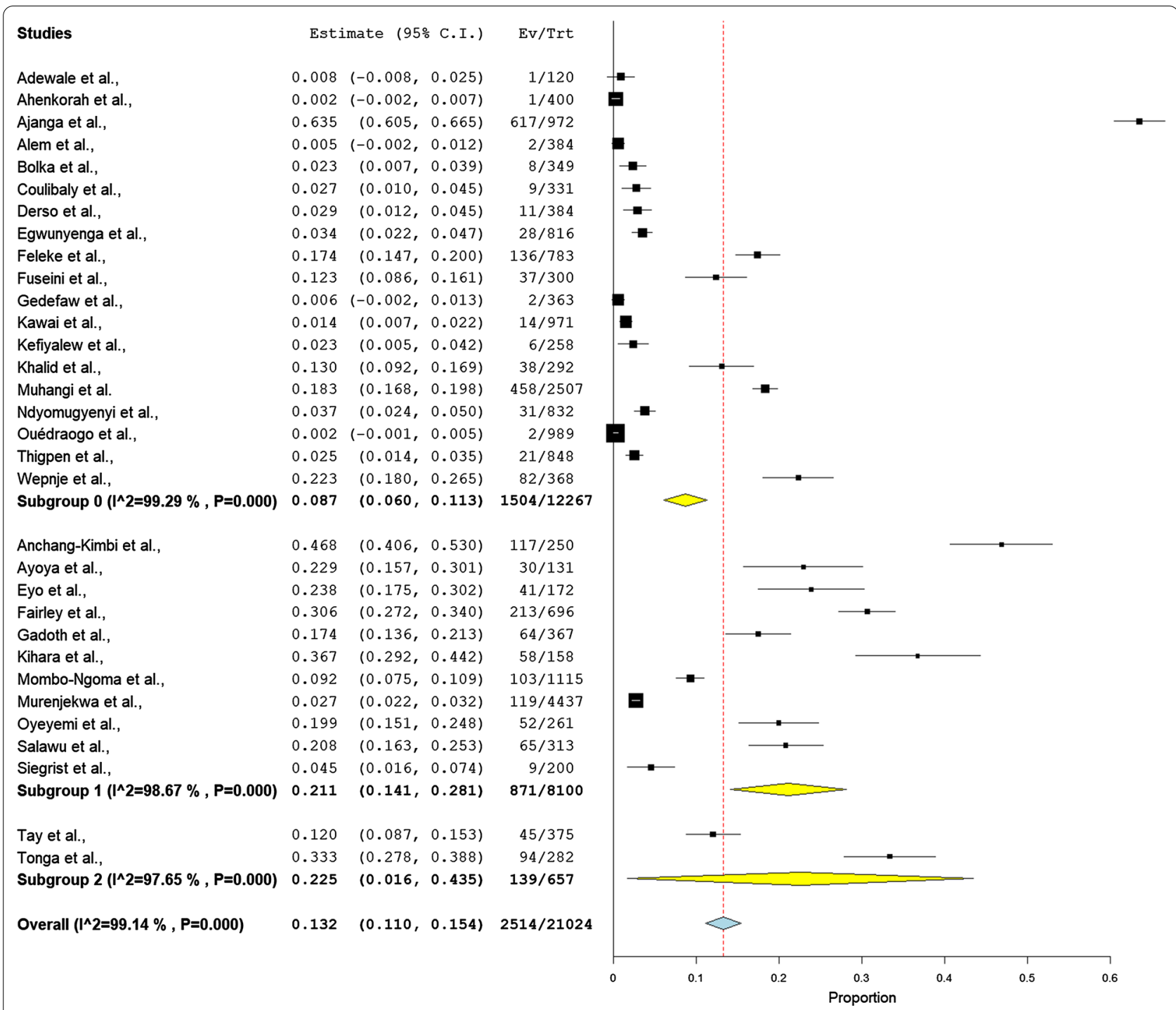

Fig. 4 Forest plots of ORs with 95\% Cls for the subgroup analysis of the type of infection in a fixed model in the meta-analysis. 


\section{Funnel Plot of Precision by Logit event rate}

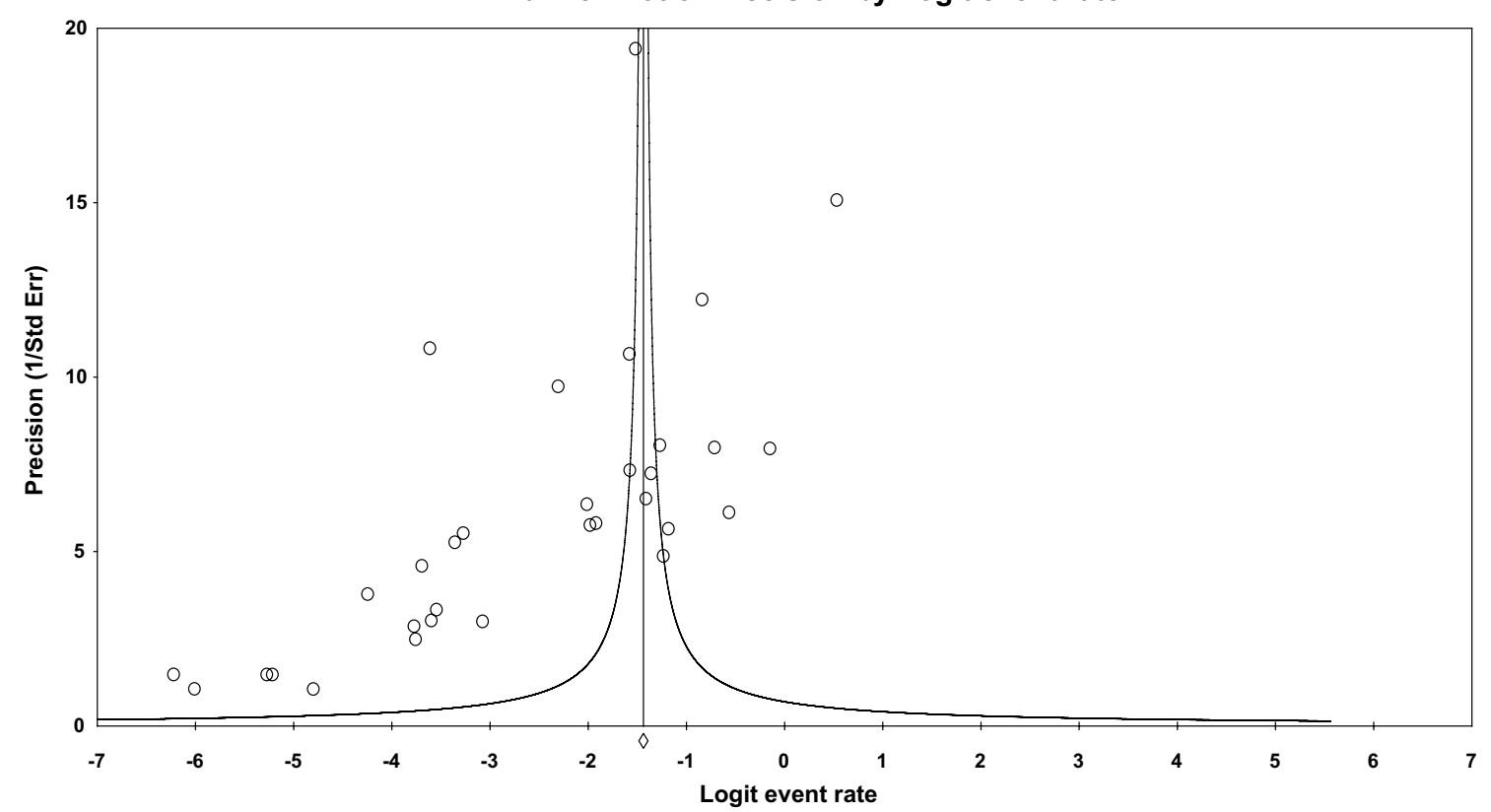

Fig. 5 Funnel plot of the publication bias

\begin{tabular}{|c|c|c|c|c|c|}
\hline Studies & Es & fimate $(95$ & $5 \%$ C.I.) & Ev/Trt & $\mathrm{Ev} / \mathrm{Ctrl}$ \\
\hline Ahenkorah et al., 2018 & 2.952 & (0.141, & $61.912)$ & $2 / 2$ & $251 / 399$ \\
\hline Bolka et al., & 6.837 & (1.357, & $34.436)$ & $6 / 8$ & $104 / 341$ \\
\hline Ayoya et al., 2006 & 2.927 & (1.243, & $6.894)$ & $20 / 30$ & $41 / 101$ \\
\hline Tay et al., 2017 & 1.653 & $(0.807$ & $3.385)$ & $34 / 45$ & $215 / 330$ \\
\hline Tonga et al., 2019 & 1.054 & $(0.607$, & $1.829)$ & $68 / 94$ & $134 / 188$ \\
\hline Anchang-Kimbi et al., 2017 & 193.435 & (11.781, & $3176.077)$ & $117 / 117$ & $73 / 133$ \\
\hline verall $\left(I^{\wedge} 2=\right.$ & 3.024 & 1.256, & $7.281)$ & $47 / 296$ & $818 / 14$ \\
\hline
\end{tabular}

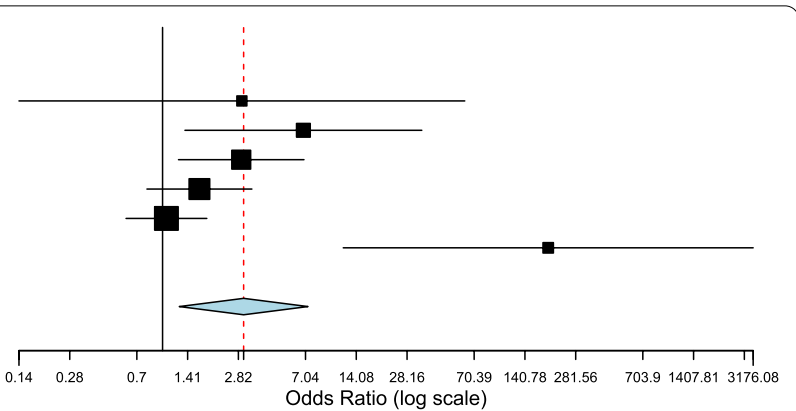

Fig. 6 Forest plots of ORs with 95\% Cls for the meta-analysis of the association of schistosomiasis with anemia using a fixed model

\section{Limitations of the study}

Many potential risk factors, such as age and parity, were not assessed in these studies. Furthermore, the cross-sectional nature of the included studies is not amenable to the dissection of the causal relationships between schistosomiasis and anemia.

\section{Conclusion}

The present meta-analysis suggests that schistosomiasis during pregnancy is an existing health problem. This meta-analysis also highlights the lack of data on the determinants and outcomes of schistosomiasis during pregnancy. Preventive measures are needed and could be part of antenatal care in areas endemic for schistosomiasis.

\section{Supplementary Information}

The online version contains supplementary material available at https://doi. org/10.1186/s13071-021-04642-4.

Additional file 1. Characteristics of all studies included in this systematic review and meta-analysis of the prevalence of schistosomiasis during pregnancy.

\section{Abbreviations}

AOR: Adjusted odds ratio; Cl: Confidence interval; GDM:SD: Deviation.

\section{Acknowledgements}

The authors would like to thank all the authors who published the manuscripts included in this work. 


\section{Authors' contributions}

IA, NAA and AHK contributed to the study design. NAA, OA and IA contributed to the data collection. IA and AHK conducted the statistical analysis. All authors read and approved the final manuscript.

\section{Funding}

None received.

\section{Availability of data and materials}

All data are included in this paper.

\section{Ethics approval and consent to participate}

This is a systematic review and meta-analysis of the published data. Hence, there is no need to obtain ethical approval.

\section{Consent for publication}

Not applicable.

\section{Competing interests:}

All authors declared that they have no competing interests.

\section{Author details}

${ }^{1}$ Department of Obstetrics and Gynecology, Unaizah College of Medicine and Medical Sciences, Qassim University, Unaizah, Kingdom of Saudi Arabia. ${ }^{2}$ Department of Family and Community Medicine, Unaizah College of Medicine and Medical Sciences, Qassim University, Unaizah, Kingdom of Saudi Arabia. ${ }^{3}$ Hamdan Bin Mohammed College of Dental Medicine, Mohammed Bin Rashid University of Medicine and Health Sciences, Dubai, United Arab Emirates.

Received: 5 July 2020 Accepted: 16 February 2021

Published online: 02 March 2021

\section{References}

1. World Health Organization. Schistosomiasis. WHO Fact Sheet. 2018. https ://www.who.int/news-room/fact-sheets/detail/schistosomiasis. Accessed Dec 20.

2. Colley DG, Bustinduy AL, Secor WE, King CH. Human schistosomiasis. Lancet. 2014;22:53-64.

3. Lacorcia M, Prazeres da Costa CU. Maternal schistosomiasis: immunomodulatory effects with lasting impact on allergy and vaccine responses. Front Immunol. 2018;2960:e234.

4. da Paz VRF, Sequeira D, Pyrrho A. Infection by Schistosoma mansoni during pregnancy: effects on offspring immunity. Life Sci. 2017;1:46-52.

5. Ag Ayoya M, Spiekermann-Brouwer GM, Traoré AK, Stoltzfus RJ, Garza C. Determinants of anemia among pregnant women in Mali. Food Nutr Bull. 2006;27:3-11.

6. Tay SCK, Nani EA, Walana W. Parasitic infections and maternal anaemia among expectant mothers in the Dangme East District of Ghana. BMC Res Notes. 2017;10:1-9.

7. Ajanga A, Lwambo NJS, Blair L, Nyandindi U, Fenwick A, Brooker S. Schistosoma mansoni in pregnancy and associations with anaemia in northwest Tanzania. Trans R Soc Trop Med Hyg. 2006;100:59-63.

8. Mombo-Ngoma G, Honkpehedji J, Basra A, Mackanga JR, Zoleko RM, Zinsou J, et al. Urogenital schistosomiasis during pregnancy is associated with low birth weight delivery: analysis of a prospective cohort of pregnant women and their offspring in Gabon. Int J Parasitol. 2017:47:69-74.

9. Friedman JF, Mital P, Kanzaria HK, Olds GR, Kurtis JD. Schistosomiasis and pregnancy. Trends Parasitol. 2007;159:64.

10. Khalid A, Abdelgadir MA, Ashmaig A, Ibrahim AM, Ahmed AAM, Adam I. Schistosoma mansoni infection among prenatal attendees at a secondary-care hospital in central Sudan. Int J Gynecol Obstet. 2012;116:10-2.

11. Gedefaw L, Ayele A, Asres Y, Mossie A. Anemia and associated factors among pregnant women attending antenatal care clinic in Wolayita Sodo Town. Southern Ethiopia Ethiop J Health Sci. 2015;25:155-62.

12. Fuseini G, Edoh DA, Kalifa BG, Knight D. Plasmodium and intestinal helminths distribution among pregnant women in the Kassena-Nankana District of Northern Ghana. 2009.
13. Fairley JK, Bisanzio D, King CH, Kitron U, Mungai P, Muchiri E, et al. Birthweight in offspring of mothers with high prevalence of helminth and malaria infection in coastal Kenya. Am J Trop Med Hyg. 2013;88:48-53.

14. Eyo JE, Onyishi GC, Okafor FC. Urinary schistosomiasis among pregnant women in some endemic tropical semi-urban communities of Anambra State. Nigeria Trop Biomed. 2012;29:575-9.

15. Gadoth A, Mvumbi G, Hoff NA, Musene K, Mukadi P, Ashbaugh HR, et al. Urogenital schistosomiasis and sexually transmitted coinfections among pregnant women in a schistosome-endemic region of the Democratic Republic of Congo. Am J Trop Med Hyg. 2019;101:828-36.

16. Muhangi L, Woodburn P, Omara M, Omoding N, Kizito D, Mpairwe H, et al. Associations between mild-to-moderate anaemia in pregnancy and helminth, malaria and HIV infection in Entebbe, Uganda. Trans R Soc Trop Med Hyg. 2007;101:899-907.

17. Kefiyalew F, Zemene E, Asres Y, Gedefaw L. Anemia among pregnant women in Southeast Ethiopia: prevalence, severity and associated risk factors. BMC Res Notes 2014;7.

18. Kihara JH, Kutima HL, Ouma J, Churcher TS, Changoma JM, Mwalisetso MA, et al. Urogenital schistosomiasis in women of reproductive age and pregnant mothers in Kwale County. Kenya J Helminthol. 2015;89:105-11.

19. Murenjekwa W, Makasi R, Ntozini R, Chasekwa B, Mutasa K, Moulton $\mathrm{LH}$, et al. Determinants of urogenital achistosomiasis among pregnant women and its association with pregnancy outcomes, neonatal deaths, and child growth. J Infect Dis. 2019;1:12.

20. Oyeyemi OT, Odaibo AB. Maternal urogenital schistosomiasis: monitoring disease morbidity by simple reagent strips. PLOS ONE. 2017;12:e0187433.

21. Siegrist D, Siegrist-Obimpeh P. Schistosoma haematobium infection in pregnancy. Acta Trop. 1992;50:317-21.

22. Ouédraogo S, Koura GK, Accrombessi MMK, Bodeau-Livinec F, Massougbodji A, Cot M. Maternal anemia at first antenatal visit: prevalence and risk factors in a malaria-endemic area in Benin. Am J Trop Med Hyg. 2012;87:418-24.

23. Tonga Z, Bayoi CN, Tchanga FC, Yengue JF, Wepnje GB, Nyabeyeu HN, Kangam $L$, et al. Schistosomiasis among pregnant women in NjombePenja health district. Cameroon J Infect Dev Ctries. 2019;13:1150-8.

24. Feleke BE, Jember TH. Prevalence of helminthic infections and determinant factors among pregnant women in Mecha district, Northwest Ethiopia: A cross sectional study. BMC Infect Dis. 2018;18:1-6.

25. Salawu OT, Odaibo AB. Schistosomiasis among pregnant women in rural communities in Nigeria. Int J Gynecol Obstet. 2013;122:1-4. https://doi. org/10.1016/j.ijgo.2013.01.024.

26. Thigpen MC, Filler SJ, Kazembe PN, Parise ME, Macheso A, Campbell CH, et al. Associations between peripheral Plasmodium falciparum malaria parasitemia, human immunodeficiency virus, and concurrent helminthic infection among pregnant women in Malawi. Am J Trop Med Hyg. 2011;84:379-85.

27. Ndyomugyenyi R, Kabatereine N, Olsen A, Magnussen P. Malaria and hookworm infections in relation to haemoglobin and serum ferritin levels in pregnancy in Masindi district, western Uganda. Trans R Soc Trop Med Hyg. 2008;102:130-6.

28. Wepnje GB, Anchang-Kimbi JK, Ndassi VD, Lehman LG, Kimbi HK. Schistosoma haematobium infection status and its associated risk factors among pregnant women in Munyenge, South West Region, Cameroon following scale-up of communal piped water sources from 2014 to 2017: a crosssectional study. BMC Public Health. 2014;2019:19.

29. Derso A, Nibret E, Munshea A. Prevalence of intestinal parasitic infections and associated risk factors among pregnant women attending antenatal care center at Felege Hiwot Referral Hospital, northwest Ethiopia. BMC Infect Dis. 2016;16:530.

30. Adewale B, Rahaman O, Aina O, Sulyman MA. Schistosoma mansoni and Soil Transmitted Helminth (STH) Infections among Pregnant Women Attending Primary Health Care Facilities in Lagos Mainland. Nigeria J Biosci Med. 2018;06:64-70.

31. Bolka A, Gebremedhin S. Prevalence of intestinal parasitic infection and its association with anemia among pregnant women in Wondo Genet district, Southern Ethiopia: a cross-sectional study.

32. Ayoya M, Spiekermann-Brouwer GM, Traoré AK, Stoltzfus RJ, Garza C. Determinants of anemia among pregnant women in Mali. Food Nutr Bull. 2006;27:3-11.

33. Ahenkorah B, Nsiah K, Baffoe P, Anto EO. Biochemical and hematological changes among anemic and non-anemic pregnant women attending 
antenatal clinic at the Bolgatanga regional hospital, Ghana. BMC Hematol. 2018;18.

34. Alem M, Enawgaw B, Gelaw A, Kenaw T, Seid M, Olkeba Y. Prevalence of anemia and associated risk factors among pregnant women attending antenatal care in Azezo Health Center Gondar Town. Northwest Ethiopia J Interdiscip Histopathol. 2013;1:137.

35. Anchang-Kimbi JK, Elad DM, Sotoing GT, Achidi EA. Coinfection with schistosoma haematobium and Plasmodium falciparum and anaemia severity among pregnant women in Munyenge, Mount Cameroon area: a cross-sectional study. J Parasitol Res. 2017;2017.

36. Coulibaly G, Yao KP, Koffi M, Ahouty BA, Louhourignon LK, N'Cho M, et al. Paludisme et parasitoses digestives chez la femme enceinte de la commune d'Abobo (Abidjan, Côte d'Ivoire). Bull la Société Pathol Exot. 2017;110:85-91.

37. Egwunyenga AO, Ajayi JA, Nmorsi OPG, Duhlinska-Popova DD. Plasmoduim/intestinal helminth co-infections among pregnant Nigerian women. Mem Inst Oswaldo Cruz. 2001;96:1055-9.

38. Kawai K, Saathoff E, Antelman G, Msamanga G, Fawzi WW. Geophagy (soil-eating) in relation to anemia and helminth infection among HIV-infected pregnant women in Tanzania. Am J Trop Med Hyg. 2009;80:36-43.

39. Moher D, Liberati A, Tetzlaff J, Altman DG. Preferred reporting items for systematic reviews and meta-analyses: the PRISMA statement. Ann Intern Med. 2009:151:264-9.

40. Munn Z, Moola S, Lisy K, Rittano D. The systematic review of prevalence and incidence data. Joanna Briggs Inst Rev Man 2014 Ed/Suppl. 2014;1-37. http://joannabriggs.org/assets/docs/sumari/ReviewersManual _2014-The-Systematic-Review-of-Prevalence-and-Incidence-Data_v2.pdf. Accessed 15 Apr 2018.

41. Wells G, Shea B, O'Connell J, Robertson J, Peterson V, Welch V et al. Newcastle Ottawa scale assess qual nonrandomised stud meta-analysis. http://www.ohri.ca/programs/clinical_epidemiology/oxfordasp. Accessed 21 June 2016.

42. Meta-Analyst O. Open Meta-Analyst - The tool | Evidence synthesis in health. https://www.brown.edu/academics/public-health/research/evide nce-synthesis-in-health/open-meta-analyst-tool. Accessed 17 Apr 2018.

43. Edwards A, Megens A, Peek M, Wallace EM. Sexual origins of placental dysfunction. Lancet. 2000;355:203-4.

44. Sedgwick P. Meta-analyses: heterogeneity and subgroup analysis. BMJ. 2013;9:89

45. Barsoum RS, Esmat G, El-BazT. Human schistosomiasis: clinical perspective: review. J Adv Res. 2013:24:433-44.

46. Salawu OT, Odaibo AB. Maternal schistosomiasis: a growing concern in sub-Saharan Africa. Pathog Glob Health. 2014;108:263-70.
47. Abioye Al, McDonald EA, Park S, Joshi A, Kurtis JD, Wu H, et al. Maternal, placental and cord blood cytokines and the risk of adverse birth outcomes among pregnant women infected with Schistosoma japonicum in the Philippines. PLoS Negl Trop Dis. 2019;13:e0007371. https://doi. org/10.1371/journal.pntd.0007371.

48. Deng Y, Qiu C, Ding H, Lu D-B. The ratio of the seroprevalence to the eggpositive prevalence of Schistosoma japonicum in China: a meta-analysis. BMC Infect Dis. 2018;18:404.

49. Gomes Casavechia MT, De Melo GDAN, Da Silva Fernandes ACB, De Castro KR, Pedroso RB, Da Silva ST, et al. Systematic review and meta-analysis on schistosoma mansoni infection prevalence, and associated risk factors in Brazil. Parasitology. 2018;298:1000-14.

50. Kurtis JD, Higashi A, Wu HW, Gundogan F, McDonald EA, Sharma S, et al. Maternal schistosomiasis japonica is associated with maternal, placental, and fetal inflammation. Infect Immun. 2011;79:1254-61.

51. Kalinda C, Mutengo M, Chimbari M. A meta-analysis of changes in schistosomiasis prevalence in Zambia: implications on the 2020 elimination target. Parasitol Res. 2020;12:33.

52. Gasim Gl, Adam I. Malaria, schistosomiasis, and related anemia. Nutr Defic. 2016;8:99.

53. Kassebaum NJ, Jasrasaria R, Naghavi M, Wulf SK, Johns N, Lozano R, et al. A systematic analysis of global anemia burden from 1990 to 2010. Blood. 1990;2014:615-24.

54. Salam RA, Cousens S, Welch V, Gaffey M, Middleton P, Makrides M, et al. Mass deworming for soil-transmitted helminths and schistosomiasis among pregnant women: a systematic review and individual participant data meta-analysis. Campbell Syst Rev. 2019. https://doi.org/10.1002/ cl2.1052.

55. McKittrick ND, Vu DM, Malhotra I, King CH, Mutuku F, LaBeaud AD. Parasitic infections in pregnancy decrease placental transfer of antipneumococcus antibodies. Clin Vaccine Immunol. 2017;24:9.

56. Ahmed AM, El Tash LA, Mohamed EY, Adam I. High levels of Schistosoma mansoni infections among schoolchildren in central Sudan one year after treatment with praziquantel. J Helminthol. 2012;86:228-32.

57. Adam I, Elwasila ET, Homeida M. Is praziquantel therapy safe during pregnancy? Trans R Soc Trop Med Hyg. 2004;98:540-3.

58. Adam I, Elwasila E, Homeida M. Praziquantel for the treatment of schistosomiasis mansoni during pregnancy. Ann Trop Med Parasitol. 2005;99:37-40.

59. Friedman JF, Olveda RM, Mirochnick MH, Bustinduy AL, Elliott AM. Praziquantel for the treatment of schistosomiasis during human pregnancy. Bull World Health Organ. 2018;96:59-65.

\section{Publisher's Note}

Springer Nature remains neutral with regard to jurisdictional claims in published maps and institutional affiliations.
Ready to submit your research? Choose BMC and benefit from:

- fast, convenient online submission

- thorough peer review by experienced researchers in your field

- rapid publication on acceptance

- support for research data, including large and complex data types

- gold Open Access which fosters wider collaboration and increased citations

- maximum visibility for your research: over $100 \mathrm{M}$ website views per year

At BMC, research is always in progress.

Learn more biomedcentral.com/submissions 